\title{
DEGRADAÇÃO AMBIENTAL E DESERTIFICAÇÃO: ANÁLISE A PARTIR DOS DADOS SOCIODEMOGRÁFICOS NOS PÓLOS DE IRECÊ E GUANAMBI ENTRE OS ANOS 2000 E 2010
}

\author{
Mariana Oliveira de Jesús ${ }^{1}$; Nacelice Barbosa Freitas ${ }^{2}$ \\ 1. Bolsista PIBIC/CNPq, Graduando do bacharelado em Geografia, Universidade Estadual de Feira de Santana, e- \\ mail: mariana.oliveira.js@gmail.com. \\ 2. Orientador, Departamento de nome, Universidade Estadual de Feira de Santana, e-mail: nacegeografic@gmail.com
}

PALAVRAS-CHAVE: Degradação; Desertificação; Migrações.

\section{INTRODUÇÃO}

O processo de desertificação decorre de mudanças climáticas e de ações antrópicas resultante do uso inadequado do solo na pecuária, agricultura, mineração, irrigação e pastoreio, definido como a o degaste do solo em áreas, semiáridas e subúmidas secas" (BRASIL, 1996,).

A região do semiárido baiano por seus aspectos ambientais: precipitação baixa e irregular, solos cristalinos, longos períodos de seca, vegetação de caatinga e cerrado, áreas pediplanadas e situação de vulnerabilidade ambiental em decorrência de práticas de uso solo sofrem com os efeitos deste processo e integram as Áreas Suscetíveis a Desertificação (ASD). A perda da capacidade produtiva dos solos, longos períodos de seca, redução de áreas agricultáveis, perda vegetação original, contaminação das águas subterrâneas, erosão, baixo níveis de renda da população e repulsão da população são consequências do processo de desertificação nas áreas degradas.

As desigualdades sociais e econômicas geradas pelo processo tende a levar a população a saírem dos seus municípios para outras regiões em função dos baixos níveis de renda e condições precárias de vida, em busca de melhores oportunidade e ofertas de emprego. Tal realidade se faz presente nos Pólos de Guanambi e Irecê, áreas de pesquisa do presente estudo.

A situação de vulnerabilidade socioeconômica e ambiental dessas áreas pesquisadas definida para a pesquisa apontam inicialmente para a necessidade da implantação de políticas públicas voltados para o desenvolvimento territorial, e a realização de estudos que visem novas produções científicas sobre os dados sociodemográficos, referentes Áreas Suscetíveis a Desertificação (ASD).

\section{MATERIAL E MÉTODOS OU METODOLOGIA (ou equivalente)}

Para o desenvolvimento da pesquisa inicialmente foi realizado um referencial teórico-metodológico sobre os conceitos de degradação ambiental, desertificação e migração. No segundo momento realizou-se a coleta de dados de população total, urbana e rural, renda e migração através dos censos Demográficos do Instituto de geografia e Estatística (IBGE). Em seguida foram confeccionados tabelas e os mapas dos Pólos, utilizando o software de geoprocessamento ArcVierw e ArcMap e a finalização auxiliado pelo Corel Draw. Posteriomente foi produzido um banco de dados referentes aos dados de população total, urbana e rural, emigração e renda média mensal dos municípios dos Pólos de Guanambi e Irecê.

Os respectivos Pólos estão localizados no Semiárido Baiano, e integram as Áreas Susceptíveis a desertificação. "O Pólo de Guanambi está localizado no Sudoeste

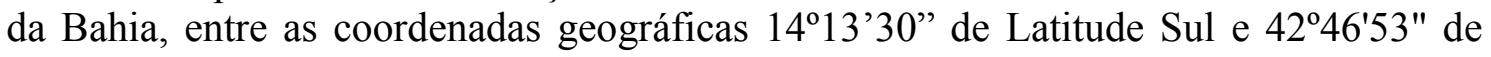


Longitude Oeste, e conta com 14 municípios: Palmas de Monte Alto, Caetité, Matina, Igaporã, Candiba, Urandi, Lagoa Real Sebastião Laranjeiras, Iuiú, Pindaí, Licínio Almeida, Guanambi, Malhada e Livramento de Nossa Senhora. O Pólo de Guanambi está localizado no Sudoeste da Bahia, entre as coordenadas geográficas $14^{\circ} 13^{\prime} 30^{\prime \prime}$ de Latitude Sul e 42\%46'53" de Longitude Oeste, e conta com 14 municípios: Palmas de Monte Alto, Caetité, Matina, Igaporã, Candiba, Urandi, Lagoa Real Sebastião Laranjeiras, Iuiú, Pindaí, Licínio Almeida, Guanambi, Malhada e Livramento de Nossa Senhora.

\section{RESULTADOS E/OU DISCUSSÃO}

\section{Pólo de Guanambi}

A partir dos dados encontrados verifica-se, entre os anos 2000 e 2010 o crescimento da população urbana dos municípios devido ao aumento do investimento nos municípios do Pólo em industrialização, comércio e serviços). Os municípios mais afetados pelo processo de desertificação são: Candiba, GuanAmbi, Iuiú, Livramento de Nossa Senhora e Malhada (JUNIOR; LOBÃO, 2011).

Cada vez mais os municípios têm perdido suas características rurais, incialmente pela quantidade da população que migra e por essa população ser em sua maioria de agricultores familiares que venderam ou perderam suas terras devido ao grande endividamento aos créditos rurais.

A degradação ambiental do Pólo levou muitos moradores a emigrar por não terem onde plantar e nem do que sobreviver, em busca de oportunidades de trabalho e melhores condições de vida. Conforme os dados do Instituto Brasileiro de Geografia e Estatística (IBGE), em 2010 a população de saída dos municípios de Irecê teve um aumento em comparação com o ano de 2000 (MAPAS 5 e 6).

A tabela 1 indica os números referentes as emigrações nos municípios do Pólo de Guanambi tendo como base os dados do IBGE (2000 - 2010),

\begin{tabular}{lcc} 
TABELA 1: EMIGRAÇÃO NOS MUNICÍPIOS DE PÓLO DE GUANAMBI \\
\cline { 2 - 3 } \multicolumn{1}{c}{ Guanambi } & $\begin{array}{c}\text { Emigrações } \\
2000\end{array}$ & $\begin{array}{c}\text { Emigrações } \\
2010\end{array}$ \\
\hline Palmas de Monte Alto & 112 & 556 \\
& & \\
Caetité & 575 & 1333 \\
Matina & 8 & 69 \\
Igaporã & 101 & 360 \\
Candiba & 74 & 467 \\
Urandi & 669 & 1281 \\
Lagoa Real & 21 & 317 \\
Sebastião Laranjeiras & 441 & 1020 \\
Iuiú & 87 & 570 \\
Pindaí & 80 & 436 \\
Licínio de Almeida & 117 & 527 \\
Guanambi & 908 & 3951 \\
Malhada & 239 & 730 \\
Livramento de Nossa Senhora & 558 & 1776 \\
\hline
\end{tabular}

Fonte: IBGE, 2000-2010

Analisando os fluxos populacionais de saída dos municípios, no ano de 2000 os municípios que tiveram menor fluxo de saída foram: Jussara, Barra do Mendes, central e Barro Alto, respectivamente 180, 181, 168 e 163 pessoas, os que apresentaram maior número de emigrações foram: Lapão. João Dourado e Irecê respectivamente com 1026, $724,2.548$ pessoas 
O rendimento mensal dos municípios do Pólo não chega a um salário mínimo no ano de 2010 as bases salariais variam entre 400,00 e 849,00 reais e no ano de 2000 tem base de menos $1 / 2$ salário mínimo, o que se torna fator de repulsão da população. Nos municípios que tem maiores rendas, foram observados os maiores números de população urbana.

\section{Pólo de Irecê}

O Pólo de Irecê recebeu muitos investimentos e incentivos de mecanização e produção agrícola do governo Federal, o que tornou um dos polos mais produzem grãos na Bahia, a alta produtividade, uso de agrotóxicos, monocultura, uso de máquinas devido aos investimentos em agriculta deu inicio ao processo de desertificação no Pólo

Essa exploração agrícola resultou no aprofundamento da degradação e redução dos recursos ambientais além de migrações principalmente da população rural para outras áreas, conforme CDAR (2004) 85\% do território de Irecê está degradado e 15\% desestabilizado por problemas causados por: uso de agrotóxicos, desmatamento, queimadas, exploração por atividade mineral e pecuária.

A degradação ambiental do Pólo levou muitos moradores a saírem dos seus locais de residência por não terem onde plantar e nem do que sobreviver, saem em busca de oportunidades de trabalho e melhores condições de vida, conforme os dados do Instituto Brasileiro de Geografia e Estatística (IBGE, 2010), em 2010 a população de saída dos municípios de Irecê teve um aumento significativo em comparação com o ano de 2000.

A tabela 2 indica os números referentes a emigração da população no Pólo de Irecê no período de 2000 e 2010.

TABELA 2: EMIGRAÇÃO NOS MUNICÍPIOS DE PÓLO DE IRECÊ (2000 - 2010)

\begin{tabular}{lcc}
\hline Municípios de Irecê & Emigrações 2000 & Emigrações 2010 \\
\hline São Gabriel & 479 & 1169 \\
Jussara & 180 & 1260 \\
Presidente Dutra & 322 & 920 \\
América Dourada & 344 & 1106 \\
Irecê & 2548 & 8876 \\
Barra de Mendes & 181 & 687 \\
Central & 168 & 934 \\
Barro do alto & 163 & 646 \\
Canarana & 511 & 1026 \\
Cafarnaum & 361 & 876 \\
Itaguaçu da Bahia & 256 & 1015 \\
Uibaí & 227 & 772 \\
Ibititá & 430 & 1446 \\
João dourado & 724 & 2534 \\
Lapão & 1026 & 2411 \\
Ibipeba & 302 & 869 \\
\hline
\end{tabular}

Fonte: IBGE, 2000-2010

Por ter como a atividade agrícola, o cultivo de grãos temporários, há uma maior quantidade de desempregados que geralmente são os agricultores que vivem dos períodos de safra, o que reduz o nível de renda da população e se torna um fator de repulsão da população. Os municípios que tem maior população vivendo em área 
urbana, a maior parte da população se fixa em áreas de maior desenvolvimento que são as áreas urbanas e as com maiores rendas.

\section{CONSIDERAÇÕES FINAIS (ou Conclusão)}

A degradação ambiental e o processo de desertificação nos Pólos de Guanambi e Irecê foram aprofundados devido ao mau uso dos solos associado às práticas de agricultura e pecuária, o que trouxe muitas implicações para os municípios como as migrações, baixos níveis de renda e redução da população. Com os períodos de estiagem e os solos degradados a renda do agricultor tende a diminuir cada vez mais e muitos como alternativa de fuga das secas e busca de melhores condições de vida e migram para outras regiões, entre os anos 2000 e 2010 que os maiores fluxos de migração foram nos grandes centros urbanos dos Pólos entre essas décadas houve o crescimento da população urbana nos centros urbanos, local que está concentrado o setor de indústria, comércio e serviços. A renda da população dos municípios não chega 1 salário mínimo e em muitos municípios é menos que 1/2 salário, o que entende-se 0 grande número de migrantes, esses números indicam a redução dos recursos para a população rural investir em atividades no campo, o que leva os agricultores a explorarem cada vez mais as áreas rurais de forma inadequada aprofundando o nível de degradação da região. Para o desenvolvimento desses Pólos é necessário elaborar para o planejamento urbano e rural que, tenha como proposta a distribuição de renda.

\section{REFERÊNCIAS}

BRASIL, Senado Federal. Conferência das Nações Unidas sobre Meio Ambiente e Desenvolvimento. Brasília: Senado Federal; Subsecretaria de Edições Técnicas, 1996.

CDAR- Companhia de Desenvolvimento e Ação Regional. Programa de Desenvolvimento Regional Sustentável da Região Irecê - PSDR IRECÊ. Salvador, 2004

JUNIOR, Israel de Oliveira; LOBÃO, Jocimara de Souza Brito. Apropriação das terras no semiárido da bahia: diagnosticando o processo de desertificação no polo de Guanambi.. Anais: XV seminário de iniciação científica, Feira de Santana, 2011. Disponível em: http://www.xvsemic.esy.es/upload/2011/2011XV-007ISR030-100.pdf. Acesso em 3 de jan de 2017

LEE,E. S. Uma teoria sobre migração. In: Migração interna: textos selecionados. Coordenador Hélio A. de Moura. Fortaleza, 1980. 